\title{
Aortic pressure wave reflection in children
}

\author{
Tomoaki Murakami, Atsuhito Takeda, Kohta Takei, Michihiko Ueno, Satoshi Yakuwa, Hirokuni Yamazawa \\ and Takuo Furukawa
}

Aortic pressure wave reflection is one of the risk factors for developing cardiovascular disease in adults, and the degree of pressure wave reflection increases with aging. However, enhanced pressure wave reflection has also been reported in infants and children. The purpose of this study was to clarify pressure wave reflection during childhood and to determine the reference for the augmentation index, which is one of the most useful parameters used to represent the degree of aortic pressure wave reflection in children. This study enrolled 72 patients with normal aortic circulation. The aortic pressure waveform was recorded using a pressure sensor-mounted catheter, and the augmentation index was thus calculated. The augmentation index tended to decrease with increasing age until around 15 years of age and then increased thereafter. For children below 15 years of age, multiple regression analysis revealed a significant negative correlation between body height and augmentation index. In children, increases in aortic pressure wave reflection are probably attributable to changes in body height.

Hypertension Research (2010) 33, 225-228; doi:10.1038/hr.2009.218; published online 8 January 2010

Keywords: augmentation index; cardiovascular disease; pressure wave reflection

\section{INTRODUCTION}

Aortic pressure augmentation caused by pressure wave reflection is a physiologically important phenomenon. It maintains constant arterial blood flow while enhancing coronary blood supply. However, excessive aortic pressure augmentation contributes to an increase in cardiovascular diseases. ${ }^{1,2}$ The augmentation index, which is obtained from the central arterial pressure waveform as the ratio of augmentation pressure to total pulse pressure, is one of the most popular tools used to evaluate the degree of the increase in aortic pressure. ${ }^{3}$ In adults, significant evidence supports a correlation between the augmentation index and cardiovascular disease. ${ }^{4-6}$

Aortic pressure augmentation increases with age in adults. ${ }^{7-9}$ However, the pressure waveforms in infants and children are similar to those in older adults. ${ }^{10,11}$ This phenomenon is explained on the basis of differences in body length and the timing of wave reflection. In children, the reflection wave returns early, not because their arterial system is stiff or pulse wave velocity is fast (as in an aged person), but because their body length is short. ${ }^{12}$ However, there has so far been no report about aortic pressure augmentation in children with normal aortic hemodynamics. The purpose of this study was to clarify the mechanism of the enhanced aortic pressure wave reflection during childhood and to determine a reference for the augmentation index in children.

\section{METHODS}

Study subjects

This study enrolled 72 patients who had undergone cardiac catheterization for small left-to-right shunt disorders (pulmonary-systemic flow ratio $<2.0$ ). Six patients whose right ventricular systolic pressure was over $40 \mathrm{~mm} \mathrm{Hg}$ (pulmonary stenosis or pulmonary hypertension) were excluded. No patient had any significant leakage at the aortic level (for example, patent ductus arteriosus, aortic regurgitation and so on), and no patient was medicated with any drugs. These patients were adopted as representative of the 'normal' aortic circulation. Aortic pressure wave reflection is influenced by obesity. To establish reference ranges from age-associated changes in aortic pressure wave reflection, the patients whose body mass index exceeded the ageand gender-specific 95th percentile were excluded. No patients demonstrated hypertension. Finally, 61 (32 male and 29 female) patients aged 0-30 (8.5 \pm 6.5$)$ years, whose pulmonary-systemic flow ratio was $1.33 \pm 0.36$, were selected for analysis (Table 1). These patients were afflicted with ventricular septal defect (41), atrial septal defect (19) and isolated partial anomalous pulmonary venous connection (1).

All subjects gave their written informed consent, and the study was approved by Hokkaido University Hospital.

Table 1 Baseline characteristics of the study participants

\begin{tabular}{lc}
\hline & $\mathrm{n}=61$ \\
\hline Gender (M/F) & $32 / 29$ \\
Age (years) & $8.5 \pm 6.5$ \\
Height (cm) & $119.7 \pm 25.1$ \\
Weight (kg) & $26.4 \pm 15.6$ \\
SBP (mm Hg) & $92.0 \pm 11.3$ \\
HR (b.p.m.) & $92.4 \pm 18.9$
\end{tabular}

Abbreviations: F, female; HR, heart rate; $\mathrm{M}$, male; SBP, systolic blood pressure. Values are mean \pm s.d. 


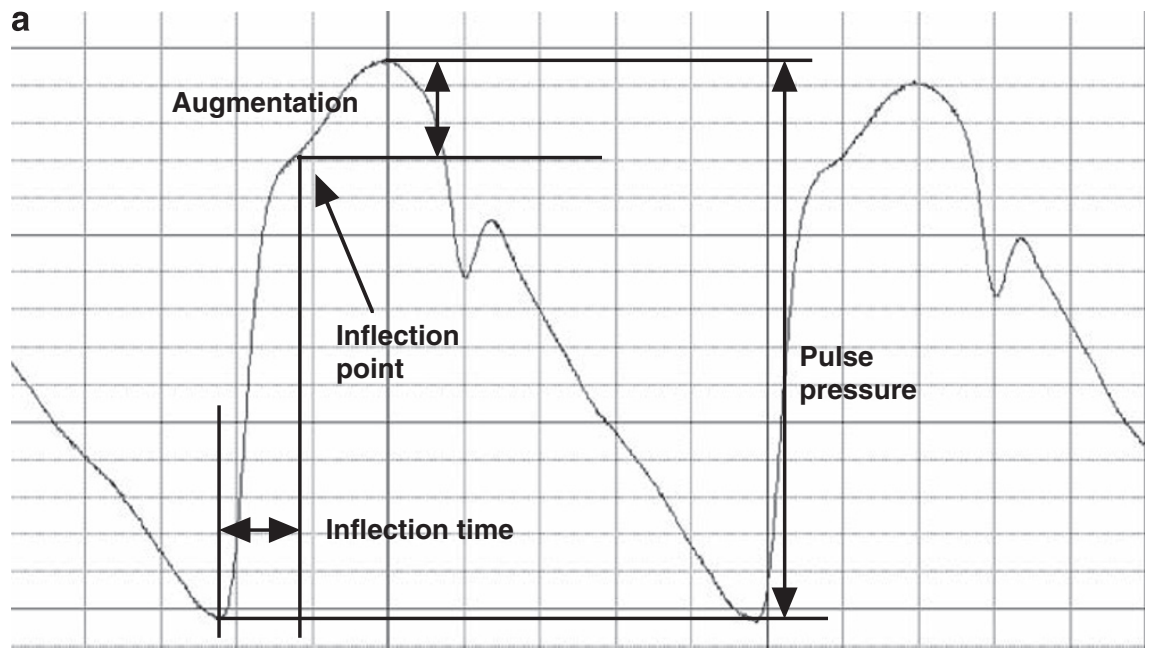

b

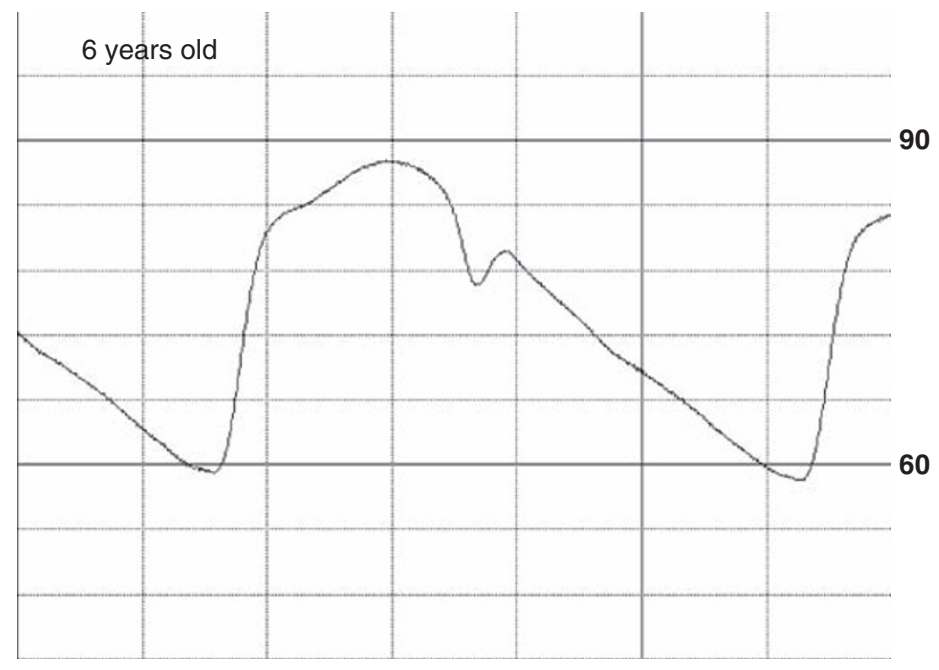

$[\mathrm{mmHg}]$

C

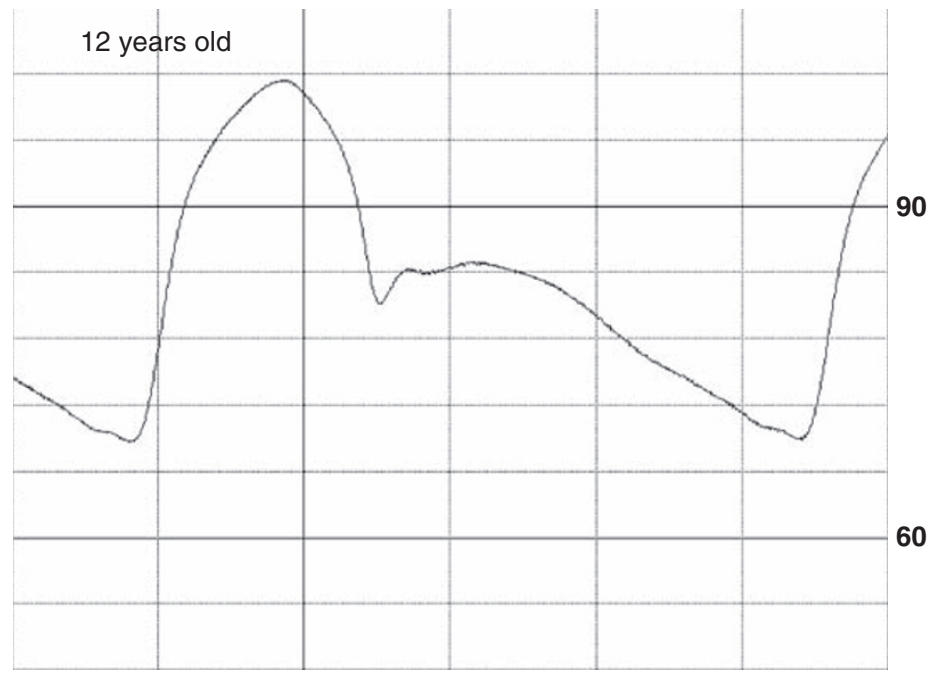

$[\mathrm{mmHg}]$

Figure 1 (a) Schematic representation of the augmentation index. The augmentation index is the ratio of augmentation to pulse pressure. (b, c) Typical ascending aortic pressure waveforms in normal aortic circulation. (b) 4 years old, body height $99.5 \mathrm{~cm}$, augmentation index $12 \%$. The reflection wave returns to the ascending aorta before aortic valve closure and enhances the left ventricular load by increasing aortic pressure in systole. (c) 12 years old, body height $163 \mathrm{~cm}$, augmentation index $-52 \%$. The reflection wave returns to the ascending aorta after aortic valve closure and thus enhances coronary blood flow. 


\section{Study protocol}

Cardiac catheterization was performed by femoral arterial puncture. Midazolam and pentobarbital were administered for sedation as required. The ascending aortic pressure was measured using a pressure sensor-mounted catheter (SPC-464D; Millar Instruments Inc., Houston, TX, USA) before the injection of any contrast material. The ascending aortic pressure waveform was recorded at 1 vertebral body thickness higher than the aortic valve. The waveform was recorded on a hard disk through an analog-digital converter, and it was also simultaneously recorded with the electrocardiogram.

\section{Pulse wave analysis}

From the recorded pressure waveforms, measurements of systolic blood pressure, diastolic blood pressure and pulse pressure were obtained for each patient. The inflection points or peaks that corresponded to early and late systolic blood pressure were obtained by multidimensional derivatives of the original pressure pulse waveforms. Using the three consecutive pressure waveforms, we measured the inflection time and an augmentation index was calculated for each patient (Figure 1a). ${ }^{7}$ Figure 1 also shows typical aortic pressure waveforms (Figures $1 \mathrm{~b}$ and $\mathrm{c}$ ). The measurements and calculations were performed using Acqknowledge (version 3.5) software (BIOPAC Systems Inc., Goleta, CA, USA).

\section{Statistical analysis}

All data are presented as the mean value \pm standard deviation. Correlations between the age and other variables were analyzed using a single regression analysis. A multiple regression analysis for the augmentation index was performed with the following parameters: age, ${ }^{12}$ gender, ${ }^{13}$ heart rate, ${ }^{14}$ body height ${ }^{15}$ and body mass index. ${ }^{16}$ A $P$-value less than 0.05 was considered statistically significant.

\section{RESULTS}

With increasing age, systolic pressure, body height and weight increased ( $r=0.50,0.86$ and 0.88 , respectively). Body height increased linearly in children below 15 years of age.

The augmentation index was $4.6 \pm 15.9 \%$. Figure 2 shows the relationship between the age and the augmentation index. This index tended to decrease with increasing age until around 15 years of age and then increase thereafter.

An analysis was performed on 53 patients below 15 years of age (30 boys and 23 girls, $6.3 \pm 3.1$ years of age, pulmonary-systemic flow ratio $1.35 \pm 0.37$ ). Their diseases were ventricular septal defect (35), atrial septal defect (17) and isolated partial anomalous pulmonary venous connection (1). The augmentation index was $6.0 \pm 16.5 \%$. Single regression analysis for the augmentation index revealed a significant negative relationship to age $(r=-0.664, P<0.0001)$, body height $(r=-0.712, P<0.0001)$ and body mass index $(r=-0.324$, $P=0.0179)$. Multiple regression analysis showed that the augmentation index was significantly associated with body height (Table 2). Figure 3 shows the relationship between body height and the augmentation index.

\section{DISCUSSION}

We found central aortic pressure augmentation to be strongly influenced by body height in children below 15 years of age.

\section{Relationship between age and augmentation index}

The present results showed that the central aortic augmentation index tended to decrease with age until the middle teens and increase thereafter. It crosses the zero line in individuals in their late $20 \mathrm{~s}$ (Figure 2). Murgo and Takazawa reported the augmentation index for ascending aorta in adults. ${ }^{7-9}$ Their data showed that the index increased with age and crossed the zero line in individuals in their late 20s. The current results are consistent with their data.

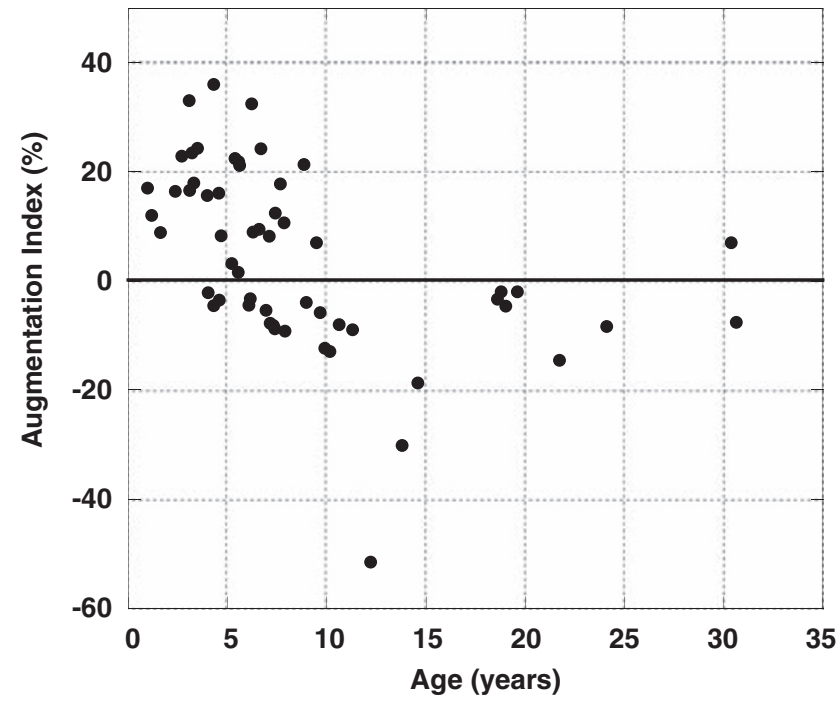

Figure 2 The relationship between age and aortic augmentation.

Table 2 Multiple regression analysis for the augmentation index

\begin{tabular}{lrrr}
\hline & $\beta$ & $t$ & P-value \\
\hline Age (years) & 0.352 & 0.746 & 0.4598 \\
HR (b.p.m.) & -0.262 & -1.920 & 0.0620 \\
Gender (male) & -0.030 & -0.278 & 0.7828 \\
Height (cm) & -1.267 & -2.617 & 0.0125 \\
BMI (kg m${ }^{-2}$ ) & 0.098 & 0.763 & 0.4502
\end{tabular}

Abbreviations: BMI, body mass index; HR, heart rate.

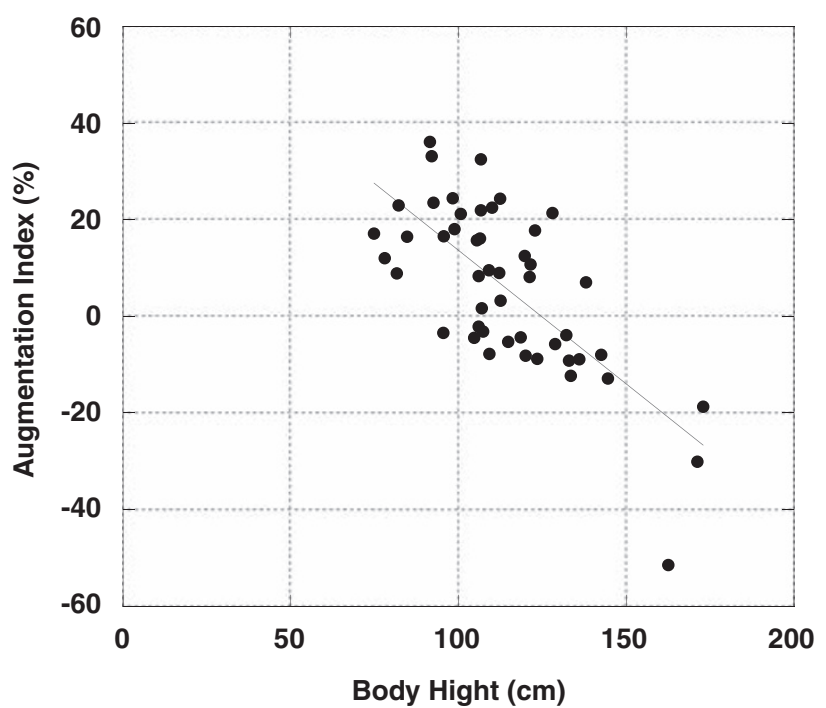

Figure 3 The relationship between body height and augmentation index in children below 15 years of age. Augmentation Index $(\%)=65.90-0.53 \times$ Body Height $(\mathrm{cm})(r=0.6838, P<0.0001)$.

Kelly et al. ${ }^{9}$ reported the relationship between age and augmentation index for the carotid artery from children and adults. They reported that the index decreased with age until 15 years and then increased after that period. The present results concerning the 
augmentation index of the ascending aorta are similar to their data for the carotid artery.

\section{Aortic pressure wave reflection in children}

Increased pressure wave augmentation in children has been reported previously. ${ }^{10,11}$ The influence of body length is considered the reason why the augmentation index is high in children and then decreases as children grow up, until 15 years of age, as seen in this study. In the present study, the body height of patients below 15 years of age increased linearly. The major reflecting point in normal aortic circulation exists in the region of the main aortic bifurcation. ${ }^{3}$ Therefore, a short body length means early return of the pressure wave reflection. Avolio et al. ${ }^{17}$ showed that the arterial distensibility decreased with age, even in children. The decrease of distensibility leads to an increase in pressure wave reflection. However, the present data showed that the augmentation index decreased with age in children below 15 years. This means that the effect of body height on augmentation index is stronger than that of decreased distensibility with aging in this age group.

The aortic augmentation index is recognized as one of the most important parameters for predicting the risk of cardiovascular diseases. However, the incidence of cardiovascular diseases is infrequent in children, even though their augmentation indices are high. We speculate that the meaning of the enhanced aortic pressure wave reflection in childhood may be related to cardiac growth. It is reasonable to assume that the enhanced pressure wave reflection is a stimulus for cardiac growth until the body height reaches its maximum.

\section{Study limitations}

We examined the aortic hemodynamic data of patients with small leftto-right shunt disorders. This study is the first report to use invasive measurements of central aortic pressure in children. It is impossible to examine the 'normal' population. Thus, we selected small left-to-right shunt patients whose aortic circulation was thought to be almost normal. The previous data on aortic pressure augmentation in adults, which were regarded as reference data, were obtained from patients with similar disorders. ${ }^{9}$

\section{CONFLICT OF INTEREST}

The authors declare no conflict of interest

1 O'Rourke MF. Arterial stiffness, systolic blood pressure, and logical treatment of arterial hypertension. Hypertension 1990; 15: 339-347.

2 Nichols WW, Edwards DG. Arterial elastance and wave reflection augmentation of systolic blood pressure: deleterious effects and implications for therapy. J Cardiovasc Pharmacol Ther 2001; 6: 5-21.

3 Nichols WW, O'Rourke MF (eds). Wave reflections. McDonald's Blood Flow in Arteries, 5th edn. Hodder Arnold: London, 2005 pp. 193-214.

4 Weber T, Auer J, O'Rourke MF, Kvas E, Lassnig E, Berent R, Eber B. Arterial stiffness, wave reflections, and the risk of coronary artery disease. Circulation 2004; 109: 184-189.

5 Kingwell BA, Waddell TK, Medley TL, Cameron JD, Dart AM. Large artery stiffness predicts ischemic threshold in patients with coronary artery disease. J Am Coll Cardiol 2002; 40: 773-779.

6 Hayashi T, Nakayama Y, Tsumura K, Yoshimaru K, Ueda H. Reflection in the arterial system and the risk of coronary heart disease. Am J Hypertens 2002; 15: 405-409.

7 Murgo JP, Westerhof N, Giolma JP, Altobelli SA. Aortic input impedance in normal man: relationship to pressure waveforms. Circulation 1980; 62: 105-116.

8 Takazawa K. A clinical study of the second component of left ventricular systolic pressure. J Tokyo Med Coll 1987; 45: 256-270.

9 Kelly RP, Hayward C, Avolio A, O'Rourke MF. Noninvasive determination of age-related changes in the human arterial pulse. Circulation 1989; 80: 1652-1659.

10 Gevers M, van Genderingen HR, Lafeber HN, Hack WWM. Accuracy of oscillometric blood pressure measurement in critically ill neonates with reference to the arterial pressure wave shape. Intensive Care Med 1996; 22: 242-248.

11 Shieh KY, O'Rourke MF, Avolio AP, Doherty B, Kelly RP, Chen Y. Pressure wave contour in the ascending aorta of children-paradoxical similarity to the elderly. Aust NZ J Med 1989; 19: 555.

12 Nichols WW, O'Rourke MF (eds). Aging. McDonald's Blood Flow in Arteries, 5th edn. Hodder Arnold: London, 2005 pp. 339-368.

13 Hayward CS, Kelly RP. Gender-related differences in the central arterial pressure waveform. J Am Coll Cardiol 1997; 30: 1863-1871.

14 Wilkinson IB, MacCallum H, Flint L, Cockcroft JR, Newby DE, Webb DJ. The influence of heart rate on augmentation index and central arterial pressure in humans. $J$ Physiol 2000; 525(Part 1): 263-270.

15 London GM, Guerin A, Pannier B, Marchais SJ, Stimpel M. Influence of sex on arterial hemodynamics and blood pressure. Role of body height. Hypertension 1995; 26: 514-519.

16 Maple-Brown LJ, Piers LS, O'Rourke MF, Celermajer DS, O'Dea K. Central obesity is associated with reduced peripheral wave reflection in Indigenous Australians irrespective of diabetes status. J Hypertens 2005; 23: 1403-1407.

17 Avolio AP, Chen S, Wang R, Zhang C, Li M, O'Rourke MF. Effects of aging on changing arterial compliance and left ventricular load in northern Chinese urban community. Circulation 1983; 68: 50-58. 